\title{
Influence of Mild Peripheral Arterial Obstructive Disease in the Functional Capacity
}

\section{Influência da Doença Arterial Obstrutiva Periférica Leve Sobre a Capacidade Funcional}

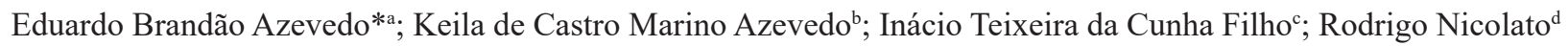

\author{
aPitágoras University, MG, Brazil. \\ ${ }^{b}$ Military Hospital of the State of Minas Gerais, MG, Brazil. \\ 'University Center of Belo Horizonte, MG, Brazil. \\ ${ }^{\mathrm{d}}$ Federal University of Minas Gerais, Stricto Sensu Graduate Program in Molecular Medicine. MG, Brazil. \\ *E-mail: brandaoazevedo@gmail.com \\ Recebido em: 28/02/19 \\ Aprovado em: 31/07/19
}

\begin{abstract}
The peripheral arterial obstructive disease (PAOD) is a chronic illnes that has as main symptom intermittent claudication and causes a progressive functional impairment of the patient. The literature is still inconclusive when it addresses the relationship among functional capacity, endurance, muscle contraction speed, and degree of blood flow impairment in patients with PAOD. The objective of this study was to evaluate the physical fitness individuals with bilateral PAOD, claudication and ankle-brachial index between 0.8 and 0.9 , to verify the impact of the disease in this outcome and to analyze the association among the tests. Forty individuals, with mean age 56 years were divided in: group PAOD $(n=20)$ and control group $(n=20)$ were subjected to the following tests: Five-Times-Sit-to-Stand Test (FTSST), Heel-rise test (HRT), test of gait speed usual (UV) and maximum (MV), shuttle walking test (SWT). There was a significant difference among the variables obtained through HRT, UV, MV and SWT, showing a worse performance of the group with PAOD compared to the control. The FTSST test showed no differences among the groups. Analyzing the whole sample, the presence of PAOD is an indicator of poor performance in TDBP. This study suggests that people with mild PAOD present reduced performance in functional endurance tests of the lower limbs and that there is a direct relationship between walking speed and patency of local arterial flow, demonstrating in an unprecedented way the need for evaluation of this public, considering the possibility of initial identification of the symptoms and giving greater efficiency in the therapeutic planning of maintenance of the functionality.
\end{abstract}

Keywords: Physical Fitness. Intermittent Claudication. Peripheral Vascular Diseases.

\section{Resumo}

A doença arterial obstrutiva periférica (DAOP) é uma doença crônica que tem como sintoma principal a claudicação intermitente e causa um progressivo comprometimento funcional do paciente. A literatura ainda é inconclusiva quando aborda a relação entre a capacidade funcional, endurance, velocidade de contração muscular e grau de comprometimento de fluxo sanguíneo em pacientes com DAOP. O objetivo deste estudo foi avaliar a aptidão fisica de indivíduos com DAOP bilateral, claudicantes e Índice tornozelo-braço entre 0,8 e 0,9, verificar o impacto da doença neste desfecho e analisar a associação entre os testes. Quarenta indivíduos, com faixa etária média de 56 anos, divididos em grupo DAOP $(n=20)$ e grupo controle $(n=20)$, foram submetidos aos testes: Teste senta-levanta (TSL), teste ponta de pé (TPP), testes de velocidade usual (VU) e máxima (VM), teste de deslocamento bidirecional progressivo (TDBP). Houve diferença significativa entre as variáveis do TPP, $V U$, VM e TDBP, mostrando pior performance do grupo com DAOP comparado ao controle. O teste TSL não apresentou diferença entre os grupos. Analisando os grupos em conjunto a presença de DAOP foi indicadora de pior desempenho no TDBP. Este estudo sugere que pacientes com DAOP leve apresentam redução da performance nos testes funcionais de endurance dos membros inferiores e que existe uma relação direta entre a velocidade da marcha e a patência do fluxo arterial local, demonstrando de forma inédita, a necessidade de avaliação deste público, considerando a possibilidade de identificação inicial dos sintomas e conferindo maior eficiência no planejamento terapêutico de manutenção da funcionalidade.

Palavras-chave: Aptidão Física. Claudicação Intermitente. Doenças Vasculares Periféricas.

\section{Introduction}

The peripheral arterial obstructive disease - PAOD is caused by stenosis or peripheral arterial obstruction of lower limbs that in $90 \%$ of cases are of atherosclerotic origin ${ }^{1}$. The main manifestation symptomatology of the disease is intermittent claudication - CI that is characterized by pain, cramp, tingling or burning sensation in the region of vascular involvement during ambulation and that, generally, ceases with the rest. This symptomatology affects the daily physical activities, limits the functional capacity, negatively affects the quality of life of this population ${ }^{1-5}$ and their physical conditioning, favoring therefore the early onset of fatigue and the futher tendency to immobility ${ }^{5-7}$. However, a large part of the individuals with POAD seeks treatment when the disease is already installed and in advanced stage, with clinical sequelae and significant deficits, both functional and emotional.

The most widespread method for indirectly assessing the blood perfusion of the lower limbs is the measurement of the 
ankle-arm index - ABI, which is the relationship between the systolic pressure in the ankle and arm systolic pressure of the respective half measured. The measurement of ABI has a sensitivity from $90 \%$ to $97 \%$ and specificity from $98 \%$ to $100 \%$ for the detection of arterial stenosis which affect $50 \%$ or more of the light of one or more arteries of larger caliber of the lower limbs, in symptomatic and asymptomatic patients, with values lower than or equal to 0.9 , in comparison with the results of angiography (gold standard), however, it has much lower cost ${ }^{8-11}$. ABI values between 0.91 to 1.30 are considered normal, and the ones above 1.30 or below 0.91 are strong predictors of diffuse atherosclerotic disease and demonstrate the presence of arterial stiffening in virtue of calcification of the medial layer of the vascular wall.

The literature is still inconclusive when it addresses the relationship among functional capacity, endurance, muscle contraction speed, and degree of blood flow impairment in patients with PAOD. There are studies that propose a direct association between the severity of the lesion and the functionality of the individual ${ }^{7-10}$. Others suggest that hemodynamic predictors limitations are not appropriate for the assessment of endurance, even less, of the functional capacity in claudicating patients ${ }^{7,11-14}$. The contradictions observed by correlacionais studies between $\mathrm{ABI}$ and functional tests reveal, in principle, a degree of independence between these conditions and, therefore, the need for specific evaluations in these areas ${ }^{6,7,11,15-17}$.

Based on the aforementioned, the objective of this study was to evaluate the physical fitness individuals with bilateral PAOD, claudicantion and ABI between 0.8 and 0.9 , to verify the impact of the disease in this outcome and to analyze the association among the tests.

\section{Material and Methods}

It is an observational, cross-sectional and controlled study, whose light group PAOD was pre-selected from 492 medical records of patients in the sector of angiology of a Hospital in Belo Horizonte. Of these 492 records, 20 individuals were selected for the light group PAOD for complying with the inclusion criteria. Then, for the control group (CG), 20 individuals were selected with gender and anthropometric characteristics similar to the PAOD group originated from the database of the caretakers of a Hospital in Belo Horizonte to be a paired control group. This study was approved by the Ethics in Research Committee of the Institute of Social Security of the Public Servers in the state of Minas Gerais on 18th of October 2007 under the record 265/07 (CAAE - 0023.0.191.000-07).

The inclusion criteria were: For the group of mild PAOD; presenting mild bilateral $\mathrm{PAOD}$, i.e., right $\mathrm{ABI}$ (ABID) and left ABI (ABIE) between 0.8 and 0.9 , diagnosed clinically and/or with the appropriate vascular exams (ex.: duplex scan, Doppler ultrasonography, Doppler vascular, angiography or arteriography) and initial signs or symptoms of IC in the story reported; for the GC; absence of diagnosis of PAOD, absence of cardiovascular diseases, uncontrolled and normal ABIE and ABID (between 0.91 and 1.3) and paired characteristics to the mild PAOD group.

Smokers, with a diagnosis of unstable angina, decompensated diabetes mellitus, uncontrolled hypertension, dyslipidemia, obese, with a recent history of pulmonary embolism, presence of ischemic changes in the electrocardiogram, with neuromuscular involvement that made it impossible to perform the physical tests, who practiced regular physical activity (non-sedentary) and who could not perform the tests proposed were excluded.

All procedures have been properly elucidated, and only after reading and signing the informed consent, the subjects were subjected to the tests.

\subsection{Procedures}

The study subjects were subjected to anamnesis and physical examination, collection of their medical history, anthropometric and demographic data.

Systolic blood pressure (SBP), diastolic blood pressure (DBP), the left and right ABI, Sit-to-Stand Test (SST), Heelrise test (HRT), test of gait speed usual (UV) and maximum (MV), shuttle walking test (SWT).

To minimize the influence of climatic variations on individuals and the tests, the tests were carried out in a neutral thermal environment $=$ (between 22 and $26^{\circ} \mathrm{C}$ ) and relative humidity between 45 to $55 \%$.

\subsection{Sit-to-Stand test}

For the evaluation of the proximal muscle resistance of the pelvic waist the TSL was used. Each participant began the test sitting in a chair and was instructed to stand up and sit down, five times as fast as possible, touching the back completely in the backrest of the chair and without the aid of the upper limbs, which in turn should stay relaxed and beside the body during the whole activity ${ }^{15}$. Two consecutive measurements were performed, with intervals of 2 minutes of rest between them. The time spent was considered as the mean of the two measurements.

\subsection{Heel-rise test}

The evaluation of the resistance of the sural muscle was done by the TPP. The participants underwent repeated plantar flexions of both ankles from the orthostatic position every 2 seconds, until muscle fatigue and/or presence of symptoms in the region of triceps surae ${ }^{18}$. To increase the reliability of the test, it was requested a first maximum flexion of ankles, it was marked the height reached by the individual, and after placing a support at the same height achieved, the individual was instructed to perform the other flexing of ankles reaching always the marking of the maximum height. The total number of plantar flexions and average, between two consecutive measurements carried out at intervals of 2 minutes of rest, were recorded. 


\subsection{Test of test of gait speed usual and maximum}

For the tests of speed individuals were requested to walk 4 meters initially at a normal speed for the record of the UV and then at a maximum speed for the VM. It was recorded the time spent on each route. In the first case, the subjects were instructed to walk "as if they were in the street going to the supermarket", and in the second, the subjects were instructed to walk as fast as they could." Each modality has been demonstrated before the completion of the same by the individuals ${ }^{19.20}$. The average between two consecutive measurements was carried out at intervals of 2 minutes of rest for each speed.

\subsection{Shuttle walking test}

The test of choice for the assessment of functional capacity with walking was the $\mathrm{SWT}^{17}$, also known as the shuttle walking test. The SWT consists of 12 levels lasting 1 minute each, and initial speed was $0.5 \mathrm{~m} / \mathrm{s}$ until a maximum speed of $2.37 \mathrm{~m} / \mathrm{sec}^{16}$. The following equipment was used: a digital chronometer Sport Timer ${ }_{\circledR}$; a portable sound device Philips $₫$ tape measure; cones; pulse oximeter NONIN ${ }^{\circledR}$ Model; Polar ${ }^{\circledR}$ heart rate monitor, model S610i; $B D{ }^{\circledR}$ sphygmomanometer and a stethoscope Littmann ${ }^{\circledR}$ Class 2 . The test was conducted in an area of 10 meters, bordered by two cones and markings on the ground at each meter. The participants were instructed to go this route, obeying the speed controlled by audio signals, until exhaustion (presence of claudicating symptom or inability to maintain the previously established rhythm). The travel speed was increased at every minute $(0.17 \mathrm{~m} / \mathrm{sec})$. Previously, general information was given about the test and made the records of SBP values and heart rate $(\mathrm{HR})$ at rest. At the end of the test, the vital data were re-evaluated, and the distance travelled. If any participant reported symptoms suggestive of IC, the time of onset of pain was then recorded. After the final calculations of the test, each patient was hydrated and forwarded to their place of rest. In SWT the variables of interest were: speed $(\mathrm{m} / \mathrm{s})$ and distance $(\mathrm{m})$ and as this test has its speed standardized, it was performed only once.

All performance tests and the functional capacity were performed on the same day, with caution to perform the SWT in the end to minimize the influence on the other tests. The tests were interrupted whenever the patient asked or when there were abnormal responses to procedures, such as: hypertensive response ( $\mathrm{BP}>230 / 120 \mathrm{mmHg}$ ), hypotensive response (a fall of more than $20 \mathrm{mmHg}$ in SBP at rest with reflex tachycardia), presence of signs or symptoms of severe fatigue or cardiovascular impairment as profuse sweating, intense dyspnea, cyanosis, mental confusion, syncope, lipothymia or any evidence judged by the examiner that could put at risk the physical integrity of the participant.

\subsection{Data analysis}

The data were analyzed using the GraphPad Prism version 4.0 for Windows. It was verified the normality of the data by the Kolmogorov-Smirnov test. When appropriate, the differences among the averages were evaluated by paired $\mathrm{t}$ test. The chi-square test $\left(x^{2}\right)$ was used to contrast ratios. Pearson's correlation coefficient was used to establish associations among the continuous variables, as well as the Spearman correlation for non-Gaussian variables. An alpha value of less than or equal to $5 \%$ was used to consider the results statistically significant. For sample size calculation, it was initially performed internal survey to establish the prevalence of PAOD mild (18.5\%), and then tailed binomial statistical test, with power of $80 \%(0.8)$ and alpha level of $5 \%(0.05)$ with the $\mathrm{z}$ value of 1.96 . Thus, the sample size was defined as 39 for comparison among the groups for each of the functional tests and 19 individuals for each linear correlation between level of disease and the functional tests.

\section{Results and Discussion}

The demographic characteristics of the study participants are shown in Table 1. There was no difference in the average age, height, weight, body mass index (BMI) and DAP among the groups. The distribution of patients according to gender was also equal among the groups, but there was a greater prevalence of women in both groups. It was recorded higher average value of PAS in the PAOD group, and as expected lower ABID and ABIE, with values that are compatible with the presence of arterial obstruction in initial level or with mild degree. The mean of BMI was $27 \mathrm{~kg} \cdot \mathrm{m}^{-2}$ in both groups, which means that, in accordance with WHO, the individuals were in a situation of overweight.

Table 1 - Sample characterization.

\begin{tabular}{|l|c|c|c|c|c|c|c|}
\hline \multirow{2}{*}{ Variable } & \multicolumn{3}{|c|}{ Mild PAOD (n=20) } & \multicolumn{3}{c|}{ Control (n= 20) } & \multirow{2}{*}{ Value $p$} \\
\cline { 2 - 8 } & Average & SD & IC-95\% & Average & SD & IC-95\% & \\
\hline Age (years) & 55.80 & 4.75 & $53.58-58,02$ & 56.05 & 3.18 & $54.56-57,54$ & 0.189 \\
\hline Gender $(\mathrm{M} / \mathrm{F})$ & $(8 / 12)$ & - & - & $(8 / 12)$ & - & - & $0.573 *$ \\
\hline Mass $(\mathrm{kg})$ & 76.07 & 10.67 & $71.07 / 81.07$ & 75.32 & 8.42 & $71.38 / 79.27$ & 0.297 \\
\hline Height $(\mathrm{cm})$ & 166.00 & 7.27 & $163.00 / 169.00$ & 167.00 & 7.17 & $164.00 / 171.00$ & 0.342 \\
\hline BMI $\left(\mathrm{kg} / \mathrm{m}^{2}\right)$ & 27.00 & 2.00 & $26.29 / 28.41$ & 27.00 & 2.00 & $26.15 / 27.55$ & 0.193 \\
\hline DBP $(\mathrm{mmHg})$ & 74.25 & 7.99 & $70.51 / 77.99$ & 73.50 & 6.70 & $70.36 / 76.64$ & 0.186 \\
\hline SBP $(\mathrm{mmHg})$ & 135.25 & 11.40 & $129.90 / 140.60$ & 124.50 & 10.37 & $119.60 / 129.40$ & 0.032 \\
\hline ABID & 0.85 & 0.03 & $0.84 / 0.88$ & 1.10 & 0.11 & $1.05 / 1.16$ & 0.027 \\
\hline ABIE & 0.86 & 0.02 & $0.86 / 0.88$ & 1.08 & 0.09 & $1.04 / 1.13$ & 0.024 \\
\hline
\end{tabular}


Table 2 presents the pharmacological classes in use by the subjects. Of 10 classes of drugs reported, 5 were used for blood pressure control (alpha-agonists, central, calcium channel antagonist, diuretics, beta-adrenergic blocker and ACE inhibitor). The remainder of the drugs used belongs to classes of antiplatelets (acetylsalicylic acid), anxiolytics, antiarrhythmic drugs, oral lipid-lowering drugs (statins) and oral analgesics.

Table 2 - Drugs in use

\begin{tabular}{|l|c|c|}
\hline \multirow{2}{*}{ Pharmacological Class } & Mild PAOD & Control \\
\cline { 2 - 3 } & $(\mathbf{n}=\mathbf{2 0})$ & $(\mathbf{n}=\mathbf{2 0})$ \\
\hline Central Ahpha-agonist & 2 & 0 \\
\hline Oral analgesic & 6 & 4 \\
\hline Anxiolytic & 3 & 0 \\
\hline Calcium channels antagonist & 1 & 0 \\
\hline Anti-Aritimic & 3 & 0 \\
\hline Acetylsalicylic acid & 2 & 1 \\
\hline Diuretic & 7 & 2 \\
\hline Statins & 3 & 0 \\
\hline Beta-Blocker & 2 & 1 \\
\hline ACE inhibitor & 3 & 1 \\
\hline
\end{tabular}

PAOD: peripheral arterial obstructive disease; ACE: angiotensinconverting enzyme.

Source: Research Data.
Table 3 reports on the arteries affected in the group of PAOD discriminated by the left lower limb (LLL) and right (RLL). The most often affected arteries were the superficial femoral artery ( 8 and 7 respectively) and the popliteal artery (4 and 5 respectively).

Table 3 - Slightly affected arteries in the PAOD group.

\begin{tabular}{|l|c|c|}
\hline \multicolumn{1}{|c|}{ Arteries Affected } & RLL & LLL \\
\hline Superficial Femoral Artery & 7 & 8 \\
\hline Fibular & 2 & 2 \\
\hline Popliteal artery & 5 & 4 \\
\hline Anteior tibial artery & 2 & 3 \\
\hline Posterior tibial arteries & 3 & 2 \\
\hline
\end{tabular}

PAOD: peripheral arterial obstructive disease.

RLL: right lower limb.

LLL: left lower limb.

Source: Research Data.

Table 4 compares the groups regarding the functional variables. It is noted that, with the exception of FTSST, the PAOD group showed significantly lower responses in relation to $\mathrm{CG}$ regarding HRT, SWT, UV, MV.

Table 4 - Difference between the light PAOD group and control regarding the functional variables

\begin{tabular}{|c|c|c|c|c|c|c|c|}
\hline \multirow{2}{*}{ Variable } & \multicolumn{3}{|c|}{ Mild PAOD $(n=20)$} & \multicolumn{3}{|c|}{ Control $(n=20)$} & \multirow{2}{*}{ Value $p$} \\
\hline & Average & SD & IC-95\% & Average & SD & IC-95\% & \\
\hline HRT & 73.6 & 49.3 & $50.47 / 96.63$ & 113.20 & 40.01 & $94.50 / 131.90$ & 0.038 \\
\hline FTSST(s) & 14.92 & 02.01 & $13.98 / 15.87$ & 13.95 & 01.57 & $13.21 / 14.69$ & 0.096 \\
\hline SWT & 337.00 & 44.48 & $316.10 /-357.80$ & 467.10 & 87.16 & $426.30 / 507.90$ & 0.028 \\
\hline $\mathrm{UV}(\mathrm{m} / \mathrm{s})$ & 01.19 & 00.08 & 01.15 / 01.23 & 01.24 & 00.07 & $01.20 / 01.27$ & 0.042 \\
\hline $\mathrm{MV}(\mathrm{m} / \mathrm{s})$ & 01.70 & 00.17 & $01.62 / 01.78$ & 01.79 & 00.14 & $01.72 / 01.85$ & 0.043 \\
\hline
\end{tabular}

PAOD : peripheral arterial obstructive disease; SD: standard deviation;IC-95\%: A confidence interval of 95\%; FTSST - Five-Times-Sit-to-Stand Test, HRT - Heel-rise test, SWT -Test of gait speed; UV - usual speed, MV- maximum speed. Statistically significant difference between the groups ( $p=0.05$ ). Source: Research Data.

Observing Table 5, which analyzes the relationship between the functional tests of the POAD group, it was found that the MV test showed the strongest and consistent correlation with the tests: HRT $(r=0.77)$, SWT $(r=0.60)$ and FTSST $(r=-0,46)$. The plantar flexions of HRT, the time spent to perform the five repetitions of the FTSST, the total distance travelled in the SWT, the MV and the UV, correlate to each other, moderately and significantly.

Table 5 - Correlation of the variables of physical fitness in the group with POAD.

\begin{tabular}{|l|c|c|c|c|}
\hline Variables & HRT (ref). & FTSST(s) & UV (m/s) & MV (m/s) \\
\hline SWT & $0,47 \dagger$ & $-0,47 \dagger$ & 0.41 & $0,60 \dagger$ \\
\hline HRT (ref). & & $-0,37 \dagger$ & 0.39 & $0,77 \dagger$ \\
\hline FTSST(s) & & & -0.41 & $-0,46 \dagger$ \\
\hline UV (m/s) & & & & 0.74 \\
\hline
\end{tabular}

PAOD: peripheral arterial obstructive disease; FTSST - Five-TimesSit-to-Stand Test rep.: repetitions, HRT - Heel-rise test, SWT Test of gait speed total distance $(\mathrm{m})$ in the SWT; MV- maximum speed $(\mathrm{m} / \mathrm{s})$ in the speed test (ST); UV - usual speed $(\mathrm{m} / \mathrm{s})$ in the speed test. $\dagger(p \leq 0.05)$.

Source: Research Data.
In the FTSST, the individuals with POAD had the number of total plantar flexions significantly lower when compared to the CG. There is not in the literature controlled studies re with public of mild PAOD, however, Uden et al., in 2005, using the unipodalic version of the FTSST to verify functionality of individuals with peripheral vascular disease, also found a worse performance of these individuals in comparison to $\mathrm{CG}^{5}$.

In a meta-analysis carried out in 2006, for senescent population $(n=33,595)$ formed mostly by Americans, Japanese, Australian and Dutch, the individuals were considered as normal regarding their performance when performing the five repetitions in the FTSST - Five-Times-Sit-to-Stand Test in established time. The results stratified by age showed: 11.4 seconds (average time of testing for individuals from 60 to 69 years), 12.6 seconds ( 70 to 79 years) and 14.8 seconds ( 80 to 89 years $)^{15}$. According to the present study and considering the meta-analysis mentioned, despite the average age of the group PAOD being approximately 56 years, their performance in the FTSST is equivalent to a normal individual of 80 to 89 years. 
In our study, the FTSST was not able to identify significant differences in performance of the proximal muscles of the pelvic waist between the groups PAOD and CG. This result suggests that both groups are below the expected performance by age, being the group with PAOD slightly more committed when compared to the CG.

For the group of PAOD, the involvement of these arteries probably hindered the patency of blood flow below the level of injury (from the middle third of the thigh to the popliteal muscle) due to the trajectory of these arteries. Thus, it is believed that the performance of the muscle groups that depend on this blood irrigation (triceps surae and origin of hamstring and popliteal muscle mainly) is impaired compared to muscle groups topographically above the level of vascular lesion (origin of the iliopsoas and rectus femoris). This information partially justifies the fact that there is no significant difference between the groups studied regarding the FTSST - Five-Times-Sit-to-Stand Test, because, in this test, the main requested musculature is the proximal muscles of the Thigh (origin of the rectus femoris) which is preserved in the group PAOD by irrigation offered by the femoral artery patent. On the other hand, the results of the FTSST, SWT, UV and MV can be due to impairment of blood irrigation of the sural muscle, the main required for performing the tests. This can also be justified by scientific reports on the progressive reduction of type I and II fibers and consequently the cross-sectional area of the gastrocnemius muscle of these patients, as well as progressive degradation of the sarcomeres mitochondrial action of muscles, which would justify the inability of individuals with POAD in performing other activities that require the use of this muscle ${ }^{21-24}$.

Several studies that use walking tests show that individuals with POAD travel smaller distances when compared to healthy individuals ${ }^{7-10}$. In our study, we found that the PAOD group presented lower total distance travelled when compared to the $\mathrm{CG}$, corroborating the data found in the literature. In a study published by Cunha-Filho et al., in 2007, 23 subjects with $\mathrm{POAD}, \mathrm{ABI}<0.8$, with a mean age of $64 \pm 11$ years and $\mathrm{BMI}=26 \mathrm{~kg} / \mathrm{m} 2$, obtained the total distance walked by the SWT of $298 \pm 132$ meters. In our study, using the same test above-cited in individuals with POAD bilaterally and with ABI between 0.8 and 0.9 , we observed that the total distance walked was $337 \pm 44$ meters and the CG obtained total distance of $467 \pm 87$ meters. This suggests that individuals with POAD and $\mathrm{ABI}$ between 0.8 and 0.9 , are worse as the distance covered when compared to individuals with ABI between 0.9 and 1.5. On the other hand, they are better functionally, when compared to individuals with $\mathrm{ABI}<0.8$, demonstrating in an unprecedented way, the need for evaluation of this target audience, considering the possibility of initial identification of symptoms and greater efficiency in the therapeutic planning of maintenance of functionality.

When comparing the data of usual speed (UV) and maximum (MV) between the PAOD and control groups, it became evident functional deficit prevalent in sick individuals of our study due to lower speeds achieved in the two modalities. Mcdermott and collaborators in 2002, using protocols for evaluation of speed similar to those described in our study, identified that the group with PAOD (ABI between 0.7 and 0.9 ), mean age of 72 years and $\mathrm{BMI}=26.5$ $\mathrm{Kg} / \mathrm{m}^{2}$, presented mean values of UV and MV $(0.9 \mathrm{~m} / \mathrm{s}$ and $1.2 \mathrm{~m} / \mathrm{s}$ ) was statistically lower when compared to the control group $(1.0 \mathrm{~m} / \mathrm{s} \text { and } 1.38 \mathrm{~m} / \mathrm{s})^{19}$. These data indicate that the POAD in groups with ABI between 0.8 and 0.9 , is already able to trigger changes in gait speed and suggests that this influence is as worse as the patency of the arterial flow site is. It is suggested, therefore, that the individual with vascular impairment induced by PAOD, tends to have a UV or MV reduced when compared to individuals without the disease.

For our public of PAOCD, the plantar flexions of the HRT, the time spent to perform the five repetitions of the FTSST, MV and UV achieved in the test of speed and the total distance travelled in the SWT proved favorable as the concurrent validity of the performance tests and, therefore, complement each other to assess the construct physical fitness. The correlations among these variables are moderate except between HRT and MV, because in this case there was strong correlation. It is suggested for this result that the recruitment of muscle groups used in both tests and its short duration can be the causes of this strong association. On the other hand, when comparing the MV with the total distance (SWT), the correlation decreases. The discrepancy among the correlations between the HRT, MV and SWT may have occurred, because, in the first case, the HRT and MV tests, are on average of short duration (+/- 1 minute). The same does not occur in the correlation between HRT and SWT, since the latter of long duration (12 minutes). Our results also indicate that tests of short duration, where there is no overload on the endurance of lower limbs as the FTSST, are not the best indicators of functionality for individuals with POAD, for not being able to demonstrate functional differences when compared to a group without POAD.

When analyzing the groups PAOD and control as the correlation between the distance walked on the SWT and the presence or not of PAOD in isolation, it was found that the presence of the disease is associated with a worse performance in the test (rho $=-0.86 ; p<0.0001$ ). The coefficient of determination $\left(\mathrm{rho}^{2}\right)$ regarding the performance (distance travelled) in the SWT was 0.88 for the group PAOD.

For future studies, tests of flexibility and muscular strength of the lower limbs should be conducted for characterization of the sample and to improve the understanding of the results found. 


\section{Conclusion}

This study demonstrated that person with POAD, even in the initial phase of signs and vascular symptoms, present a reduction in the performance in functional tests SWT, HRT, $\mathrm{UV}$ and MV and suggests that tests of endurance of lower limbs, low cost of implementation, are good indicators of functionality for subjects with mild POAD. Our data also indicate that even in mild arterial involvement the gait speed will be lower the lower the patency of the arterial flow site.

This study suggests that patients with mild peripheral arterial disorders also require attention regarding screening and preventive actions, therefore, it is possible that already present physical losses compared to individuals without the disease. Therefore, we would be contributing to these individuals remain active in society and remain preserved their daily living and instrumental activities for a longer time.

\section{References}

1. Bradberry JC. Peripheral arterial disease: phatophysiology, risk factors and role of antithrombotic therapy. J Am Pharm Assoc 2004:44:37-45. doi: 10.1331/154434504322904596

2. Cimminiello C. PAD epidemiology and pathophysiology. Thrombosis Res 2002:106;295-301. doi: 10.1016/S00493848(01)00400-5

3. Gardner A W, Montgomery PS, Killewich LA. Natural history of physical function in older men with intermitent claudication. J Vascular Surg 2004;40(1):73-8. doi: 10.1016/j. jvs.2004.02.010

4. Atkins LM, Gardner AW. The relationship between lower extremity function strength and severity of peripheral arterial disease. Angiology 2004;55(4):347-55.doi: $10.1177 / 000331970405500401$

5. Hamburg NM, Creager MA. Pathophysiology of intermittent claudication in peripheral artery disease. Circ J 2017; 81:2819. doi:10.1253/circj.cj-16-1286

6. Van Uden CJ, Van der Vleuten CJ, Kooloos JG, Wollwesheim H. Gait and calf muscle endurance in patients with chronic venous insufficiency. Clin Rehabil 2005;19(3):339-44. doi: 10. $1191 / 0269215505 \mathrm{cr} 809$ oa

7. Mcdermott MM, Greenland P, Liu K, Guralnik JM, Criqui $\mathrm{MH}$, Chan C, et al. The ankle brachial index is associated with leg functional and physical activity: The walking and leg circulation study. Ann Int Med 2002;136(12);873-83. doi: 10.7326/0003-4819-136-12-200206180-00008

8. Mcdermott MM, Guralnik JM, Albay M, Bandinelli S, Miniati B, Ferrucci L. Impairments of muscle in nerves associated with peripheral arterial disease and their relationship with lower extremity functioning: The Inchianti Study. J Am Geriatrics Soc 2004;52(3):405-10. doi: 10.1111/j.15325415.2004.52113.x

9. Mcdermott MM, Liu K, Greenland P, Guralnik JM, Criqui, Chan C, et al. Functional decline in peripheral arterial disease. Association with the ankle brachial index and leg syntoms. JAMA 2004;292(4):453-61. doi: 10. 1001/jama.292.4.453

10. Mcguigan MRM, Bronks R, Newton RU, Sharman MJ, Graham JC, Cody DV, et al. Muscle fiber characteristics in patients with peripheral arterial disease. Med Scie Sports Exercise 2001:33(12);2016-2021.doi: 10.1097/0000576820112000-0007
11. AlGhatrif M, Zane A, Oberdier M, Canepa M, Studenski S, Simonsick E, et al. Lower mitochondrial energy production of the thigh muscles in patients with low-normal ankle-brachial index. J Am Heart Assoc 2017;6: e006604. doi:10.1161/ jaha.117.006604

12. Mcdermott MM, Criqui MH, Grennland P, Guralnik JM, Liu K, Pearce WH, et al. Leg strenght in peripheral arterial disease: associations with severity and lower-extremity performance. J Vascul Surg 2004;39(3):523-30. doi: 10.1016/j.jvs.2003.08.038

13. Green S. Haemodynamic limitations and exercise performance in peripheral arterial disease. Clin Physiol Functional Imaging 2002;22(2):81-91. doi: 10.1046/j.13652281.2002.00400.x

14. Szuba A, Oka RK, Harada R, Cooke JP. Limb hemodynamics are not predictive of functional capacity in patients with PAD. Vascular Med 2006;11(3):55-163. doi: $10.1177 / 1358863 \times 06074828$

15. Bohannon RW. Reference values for the five-repetition sitto-stand test: a descriptive meta-analysis of data from elders. Percept Motor Skills 2006;103(1):215-22. doi: 10.2466/ pms.103.1.215-222

16. Cunha-Filho IT, Pereira DA, Carvalho AM, Campedeli L, Soares M, Sousa Freitas J. The reliability of walking tests in people with claudication. Am J Phys Med Rehabil 2007;86(7):1-9. doi: 10.1097/PHM.0b013e31806de721

17. Payne GE, Skehan JD. Shuttle walking test: a new approach for evaluating patients with pacemakers. Heart (British Cardiac Society) 1996;75(4):14-8. doi: 10.1136/hrt.75.4.414

18. Pereira AGD, Oliveira KL, Cruz JO, Souza CG, Cunha Filho IT. Reproducibility of functional tests in peripheral arterial disease. Fisioter Pesq 2008;15(3):228-34. doi: 10.1590/ S1809-29502008000300003

19. Mcdermott MM, Liu K, Ferrucci L, Criaqui MH, Greenland $\mathrm{P}$, Guralnik JM, et al. Physical performance in peripheral arterial disease: A slower rate of decline in patients who walk more. Ann Int Med 2006;144(1):10-20. doi: 10.1016/s01620908(08)70399-4

20. Guralnik JM, ferrucci L, Simonsick EM, Salive ME, Wallace RB. Lower-extremity function in persons over the age of 70 years as a predictor of subsequent disability. New England J Med 1995;332(9):556-61. doi: 10.1056/ NEJM199503023320902

21. Pedrinelli R, Marino L, Dell'omo G, Siciliano G, Rossi B. Altered surface myoeletric signals in peripheral vascular disease: correlations with muscle fiber composition. Muscle Nerve 1998;21:201-10. doi:10.1002/(sici)10974598(199802)21:2<201::aid-mus7>3.0.co;2f

22. Mcdermott MM, Greeland P, Ferrucci L, Criqui MH, Liu K, Sharma L, et al. Lower extremity performance is associated with daily life physical activity in individuals with and without peripheral arterial disease J Am Geriatr Soc 2002;50(2);24755. doi: 10.1046/j.1532-5415.2002.50055.x

23. McDermott MM. Medical management of functional impairment in peripheral artery disease: a review. Progress Cardio Dis 2018;60(6):586-92. doi: 10.1016/j. pcad.2018.03.007

24. McDermott MM, Peterson CA, Sufit R, Ferrucci L, Guralnik JM, Kibbe MR, et al. Peripheral artery disease, calf skeletal muscle mitochondrial DNA copy number, and functional performance. Vasc Med 2018;23(4):340-8. doi: $10.1177 / 1358863 \times 18765667$ 